Article

\title{
Perindopril Induces TSP-1 Expression in Hypertensive Patients with Endothelial Dysfunction in Chronic Treatment
}

\author{
Valentina Buda ${ }^{1,+}{ }^{,}$Minodora Andor ${ }^{2, \dagger}$, Lucian Petrescu ${ }^{2, *}$, Carmen Cristescu ${ }^{1, *}$, \\ Dana Emilia Baibata ${ }^{2}$, Mirela Voicu ${ }^{1}$, Melania Munteanu ${ }^{3}$, Ioana Citu ${ }^{2}$, Calin Muntean ${ }^{2}$, \\ Octavian Cretu ${ }^{2}$ and Mirela Cleopatra Tomescu ${ }^{2}$ \\ 1 Faculty of Pharmacy, Victor Babeş University of Medicine and Pharmacy, 2 EftimieMurgu, 300041 Timisoara, \\ Romania; buda.valentina.oana@gmail.com (V.B.); mavoicu@yahoo.com (M.V.) \\ 2 Faculty of Medicine, Victor Babeş University of Medicine and Pharmacy, 2 EftimieMurgu, 300041 Timisoara, \\ Romania; andorminodora@gmail.com (M.A.); danaemilia@yahoo.com(D.E.B); citu.ioana@umft.ro (I.C.); \\ calin.muntean@gmail.com (C.M); tavicretu@yahoo.com (O.C.); tomescu.mirela@umft.ro (M.C.T.) \\ 3 Faculty of Pharmacy, VasileGoldis Western University, 86 LiviuRebreanu, 310045 Arad, Romania; \\ anaionescuro@yahoo.com \\ * Correspondence: petrescu_lucian@yahoo.com (L.P.); carmencristescu@umft.ro (C.C.); \\ Tel.: +40-256-207-355 (L.P.); +40-256-494-604 (C.C.) \\ + These authors contributed equally to this work.
}

Academic Editor: William Chi-shing Cho

Received: 7 December 2016; Accepted: 30 January 2017; Published: 7 February 2017

\begin{abstract}
Thrombospondin-1 (TSP-1) is a potent endogenous inhibitor of both physiological and pathological angiogenesis, widely studied as a target in drug development for treating cancer. Several studies performed in the cardiovascular field on TSP-1 are contradictory, the role of TSP-1 in the physiopathology of cardiovascular disorders (CVDs) being, for the moment, incompletely understood and may be due to the presence of several domains in its structure which can stimulate many cellular receptors. It has been reported to inhibit NO-mediated signaling and to act on the angiogenesis, tissue perfusion, endothelial cell proliferation, and homeostasis, so we aimed to quantify the effect Perindopril has on TSP-1 plasma levels in hypertensive patients with endothelial dysfunction in comparison with other antihypertensive drugs, such as beta blockers, calcium channel blockers, and diuretics, in a chronic treatment. As a conclusion, patients under treatment with Perindopril had increased plasma levels of TSP-1 compared with other hypertensive patients and with the control group. The results of this study confirms the pleiotropic properties of Perindopril: anti-proliferative, anti-inflammatory, with effects showed by quantifying a single biomarker: TSP-1.

Keywords: TSP-1; thrombospondin-1; endothelial dysfunction; essential arterial hypertension; perindopril; antihypertensive drugs; anti-inflammatory; anti-proliferative; angiotensin-converting enzyme (ACE) inhibitors
\end{abstract}

\section{Introduction}

Thrombospondin-1 (TSP-1) is a potent endogenous inhibitor of both physiological and pathological angiogenesis, widely studied as a target in the drug development for treating cancer. Recently, studies showed that it also inhibits NO-mediated signaling. Thus, it acts on angiogenesis, tissues perfusion, endothelial cell proliferation, and homeostasis [1-4].

TSP-1 is the most studied member of the family of thrombospondins, a family which consists of five multimeric, multidomain calcium-binding glycoproteins that act as regulators of cell-cell and 
cell-matrix associations, which interact with other extracellular matrix molecules that can influence their function [5].

A major source of TSP-1 is the alpha-granules of platelets which release this substance upon activation. It is also present in various cell types, such as endothelial cells, vascular smooth muscle cells, macrophages, and cardiomyocites [6-10]. It is involved in many processes that regulate cellular adhesion, migration, cell proliferation, apoptosis, vascular systemic tone, and cytosckeletal organization [11,12]. Being constitutively present within the blood vessels, it interacts with many important proteins that are involved in maintaining homeostasis and the vascular structure. This has been classified as a counter-adhesive protein that is capable of interacting with various cell-surface receptors, growth factors, bioactive molecules, proteases, and several studies have shown its implications in the pathogenesis of many cardiovascular diseases [2,13-19].

The studies performed in the cardiovascular field on thrombospondin-1 are contradictory and often conflicting, the role of TSP-1 in the physiopathology of cardiovascular disorders (CVDs) being far from completely understood. This controversy upon the effects of TSP-1 reported in various cell types may be due to the presence of several domains in its structure that can stimulate many cellular receptors $[5,6,18,19]$.

TSP-1, a homotrimeric glycosylated protein of a $450 \mathrm{kDa}$, consists of $\mathrm{N}$-terminal and C-terminal globular domains, connected by a thin strand. The N-terminal domain can be cleaved by several proteases, such as thrombin, trypsin, and plasmin; therefore, it can exist in a soluble state or associated with activated platelet membranes [19-21]. The C-terminal region allows it to form covalent bonds with other proteins (e.g., thrombin). The cellular receptors with which the thrombospondin-1 can interact include: CD36, CD47 (integrin associated protein), proteoglycans, and various integrins [6,22]. As we already mentioned it, the N-terminal domain present in the structure of TSP-1 has a heparin binding domain that can bind to heparin sulphate proteoglycans [23], the peptide sequence CSVTCG interacts with CD36 [24], and the C-terminal domain binds to CD47 [25]. TSP-1 can also bind to components of fibrinolytic system (e.g., plasminogen, an inhibitor of plasminogen activator inhibitor-1, urokinase), to cathepsin $G$, to various integrins $(\alpha 3 \beta 1, \alpha \operatorname{Ilb} \beta 3)$, and to elastase [26,27]. By binding to CD36 (the primary TSP-1 receptor, expressed on a variety of cells), TSP-1 induces anti-angiogenic and inflammatory actions, platelet aggregation, and adhesion to endothelial cells [20].

TSP-1 stimulation of CD47 (a member of immunoglobulin superfamily, component of the $\beta 3$ integrin complex, expressed on $\mathrm{T}$ cells and polymorphonuclear cells, having a role in maintaining immune tolerance) induces the inhibition of releasing IL-2 [28,29]. The C-terminal domain of TSP- 1 that is bound to CD47 mediates an anti-proliferative effect on vascular smooth muscle cells (VSMCs) [1].

TSP-1 can also stimulate and activate TGF (transforming growth factor)- $\beta_{1}$, being the only member of its family capable to perform this action. Summarizing all of the information presented above, the role of TSP- 1 in the cardiovascular disorders is far from being elucidated and understood and it probably depends on the exact physiopathological condition and on the context of its expression $[5,6,19]$.

In this study, we aimed to quantify the variations of the TSP-1 plasma levels under different antihypertensive regimens, in hypertensive patients with endothelial dysfunction.

Having, as a starting point, the fact that Perindopril not only decreases hypertension, but it also possesses pleiotropic properties (due to the accumulation of bradykinin), by which it ameliorates the endothelial dysfunction, this study, therefore, compares its effect on TSP-1 plasma levels versus other antihypertensive regimens, as a chronic treatment, in patients with hypertension (HTN) and endothelial dysfunction (ED).

\section{Results}

Table 1 shows the clinical and demographic characteristics of all 351 patients included in this study. The two hypertensive groups ( $B$ and $C$ ) were similar in terms of age, blood pressure, and sex distribution, although the duration of hypertension was greater in Group B (patients treated with 
other antihypertensive medication, except Perindopril), without any statistical significance between the groups.

Table 1. Characteristics of the control and study groups.

\begin{tabular}{ccccc}
\hline Parameters & Group A $(\boldsymbol{n}=\mathbf{1 0 5})$ & Group B $(\boldsymbol{n}=\mathbf{1 1 7})$ & Group C $(\boldsymbol{n}=\mathbf{1 2 9})$ & $\boldsymbol{p}$ \\
\hline Age (years) & $55.13 \pm 14.59$ & $62.24 \pm 13.54(1)$ & $61.24 \pm 12.3(1)$ & $<0.001$ \\
Men & $55(105)$ & $48(117)$ & $57(129)$ & 1 \\
Women & $50(105)$ & $69(117)$ & $72(129)$ & - \\
HTN duration (months) & - & $107.61 \pm 86.47(1)$ & $104.00 \pm 77.18(1)$ & 0.729 \\
SBP (mmHg) & $122.53 \pm 17.81$ & $139.58 \pm 18.16(1)$ & $139.88 \pm 16.39(1)$ & $<0.001$ \\
DBP (mmHg) & $76.75 \pm 9.95$ & $83.69 \pm 13.68(1)$ & $84.51 \pm 10.76(1)$ & $<0.001$ \\
Heart rate (beats/min) & $70.23 \pm 8.46$ & $76.19 \pm 10.84(2)$ & $69.14 \pm 7.18(2)$ & $<0.001$ \\
\hline
\end{tabular}

Data are represented as mean \pm standard deviation (SD). HTN: hypertension, SBP: systolic blood pressure, DBP: diastolic blood pressure. Statistical significance was considered at a $p$-value $<0.05$. (1) A significant difference when compared with the control group; (2) A significant difference between both hypertensive groups.

Table 2 shows the biochemical data for all of the groups. A significant difference between groups can be noticed in what concerns the cholesterol level of Group C (patients under treatment with Perindopril), due to a possible mild dislipidemia. Additionally, the creatinine levels were higher in this group, with mild renal impairment being one of the first choices for angiotensin-converting enzyme (ACE) inhibitors in hypertensive patients, as a result of their action of decreasing the proteinuria and offering renal protection due to the amelioration of ED.

Table 2. Biochemical data among the patients in the study groups.

\begin{tabular}{ccccc}
\hline Parameters & Group A $(\boldsymbol{n = 1 0 5})$ & Group B $(\boldsymbol{n = 1 1 7})$ & Group C $(\boldsymbol{n = 1 2 9 )}$ & $p$ \\
\hline ALAT (U/L) & $39.19 \pm 15.63$ & $40.07 \pm 15.49$ & $42.58 \pm 16.12$ & 0.226 \\
ASAT (U/L) & $24.82 \pm 9.16$ & $23.97 \pm 8.35$ & $25.38 \pm 10.65$ & 0.509 \\
Cholesterol (mg/dL) & $198.10 \pm 55.44$ & $203.30 \pm 51.75(2)$ & $216.47 \pm 59.44(2)$ & 0.03 \\
Triglicerides (mg/dL) & $124.00 \pm 72.6$ & $148.21 \pm 95.61$ & $135.91 \pm 57.62$ & 0.347 \\
Glucose (mg/dL) & $110.16 \pm 50.63$ & $112.80 \pm 45.73$ & $109.69 \pm 21.23$ & 0.814 \\
Creatinine (mg/dL) & $0.85 \pm 0.22$ & $0.87 \pm 0.20(2)$ & $0.96 \pm 0.30(2)$ & $<0.001$ \\
Potassium (mmol/L) & $4.36 \pm 0.40$ & $4.25 \pm 0.46$ & $4.38 \pm 0.44$ & 0.06 \\
INR & $1.16 \pm 0.32$ & $1.06 \pm 0.25$ & $1.29 \pm 1.37$ & 0.11 \\
ESR (mm/h) & $9.16 \pm 5.47$ & $13.21 \pm 7.75(2)$ & $16.72 \pm 13.79(2)$ & $<0.001$ \\
BUN (mg/dL) & $18.43 \pm 6.48$ & $17.66 \pm 7.04$ & $18.84 \pm 6.81$ & 0.391 \\
\hline
\end{tabular}

Data are represented as mean \pm SD. Statistical significance was considered at a $p$-value $<0.05$. (1) A significant difference when compared with the control group; (2) A significant difference between both hypertensive groups. ALAT: alanine aminotransferase (GTP). ASAT: aspartate aminotransferase (GOT). INR: international normalized ratio. ESR: erythrocyte sedimentation rate. BUN: blood urea nitrogen.

Furthermore, it can be noticed that a higher level of systemic inflammation in Group C was statistically significant, reflected through the erythrocyte sedimentation rate (ESR) levels.

Concerning the other parameters, there were no significant statistical differences between the groups having the plasma values being in the normal range.

Table 3 shows the principal indicators of the presence/absence of ED in the three groups. The patients from Group A had no endothelial dysfunction (reflected throughout the flow mediated vasodilatation-FMD value), compared with the other two groups of hypertensive patients. In Group B, the degree of ED was higher, compared with Group C and statistically significant. The plasma levels of high-selectivity $C$ reactive protein were higher in Group C, compared with the levels of other groups, and also the number of people who were smokers was higher in this group. The TSP-1 plasma level was also the highest in this group, being very close to the value considered statistical significant $(p<0.05)$. The intima-media thickness (IMT) values were greater in both groups 
of hypertensive patients. Additionally, the pentraxin-3 (PTX3) plasma levels were the smallest in the $\mathrm{C}$ group who were under treatment with perindopril.

Table 3. The principal indicators of the presence/absence of ED.

\begin{tabular}{ccccc}
\hline Parameters & Group A $(\boldsymbol{n}=\mathbf{1 0 5})$ & Group B $(\boldsymbol{n}=\mathbf{1 1 7})$ & Group C $(\boldsymbol{n}=\mathbf{1 2 9})$ & $p$ \\
\hline hs-CRP $(\mathrm{mg} / \mathrm{dL})$ & $0.26 \pm 0.35$ & $0.26 \pm 0.25$ & $0.40 \pm 0.56$ & 0.007 \\
Pentraxin-3 $(\mathrm{ng} / \mathrm{mL})$ & $1.43 \pm 1.35$ & $1.35 \pm 1.24$ & $0.89 \pm 0.58$ & $<0.001$ \\
Thrombospondin-1 $(\mathrm{ng} / \mathrm{mL})$ & $10882 \pm 7290$ & $10221 \pm 6141.7$ & $12117 \pm 6895$ & 0.08 \\
FMD $(\%)$ & $20 \pm 0.3$ & $10.63 \pm 0.3$ & $14 \pm 0.03$ & $<0.001$ \\
ED & absent & present & present & - \\
CC IMT right $(\mathrm{mm})$ & $0.83 \pm 0.26$ & $0.92 \pm 0.19$ & $0.95 \pm 0.21$ & $<0.001$ \\
CC IMT left $(\mathrm{mm})$ & $0.83 \pm 0.21$ & $0.95 \pm 0.18$ & $0.92 \pm 0.18$ & $<0.001$ \\
BMI $\left(\mathrm{kg} / \mathrm{m}^{2}\right)$ & $23.94 \pm 3.77$ & $26.48 \pm 4.00$ & $28.06 \pm 3.44$ & $<0.001$ \\
Smokers & $21(105)$ & $18(117)$ & $30(129)$ & - \\
\hline
\end{tabular}

Data are represented as mean \pm SD. Statistical significance was considered at a $p$-value $<0.05$. hs-CRP: high-sensitivity C-reactive protein. PTX3: pentraxin-3. TSP-1: thrombospondin-1. FMD: flow mediated vasodilatation. ED: endothelial dysfunction. CC IMT: common carotid intima-media thickness. BMI: body mass index.

The echocardiography showed a septal hypertrophy for all hypertensive patients (IVS $>11 \mathrm{~mm}$ ) compared with the control group, without any statistical significance between the three groups. (Table 4). All of the other echocardiographic parameters were within their normal range, in all three groups, without any significant difference.

Table 4. Echocardiography data in different study groups.

\begin{tabular}{ccccc}
\hline Parameters & Group A $(\boldsymbol{n = 1 0 5 )}$ & Group B $(\boldsymbol{n}=\mathbf{1 1 7})$ & Group C $(\boldsymbol{n = 1 2 9})$ & $\boldsymbol{p}$ \\
\hline DLA $(\mathrm{mm})$ & $35.17 \pm 6.88$ & $37.61 \pm 7.54$ & $36.46 \pm 5.70$ & 0.02 \\
IVS $(\mathrm{mm})$ & $10.76 \pm 2.50$ & $11.35 \pm 2.26$ & $11.25 \pm 1.82$ & 0.103 \\
PWLV $(\mathrm{mm})$ & $10.04 \pm 1.60$ & $10.40 \pm 1.85$ & $10.88 \pm 1.53$ & $<0.001$ \\
EDLV (mm) & $49.8 \pm 6.79$ & $52.56 \pm 5.42$ & $50.93 \pm 4.82$ & 0.001 \\
E.F. (\%) & $56.01 \pm 8.22$ & $53.10 \pm 8.65$ & $55.46 \pm 7.91$ & 0.01 \\
S.F. (\%) & $29.14 \pm 5.80$ & $28.10 \pm 7.11$ & $29.11 \pm 5.01$ & 0.322 \\
\hline
\end{tabular}

Data are represented as mean \pm SD. Statistical significance was considered at a $p$-value $<0.05$. DLA: diameter of left atrium. IVS: diameter of interventricular septum. PWLV: posterior wall of the left ventricle. EDLV: end diastolic diameter of left ventricle. EF: ejection fraction. S.F.: shortening fraction.

The analyses performed in order to determine the correlations between the plasma levels of TSP-1 and other parameters in both groups of hypertensive patients, and in the control group (Tables 5-7) showed that TSP-1 correlated positively $(r>0.3)$ only in Group B, with tryglicerides, leucocites, and neutrophils. 
Table 5. Correlation of TSP-1 plasma levels with all data in Group C.

\begin{tabular}{ccc}
\hline Parameters & Thrombospondin-1 & Correlation \\
\hline Age (years) & - & $r=0.025, p<0.001$ \\
HTN duration (months) & - & $r=0.022, p<0.001$ \\
SBP $(\mathrm{mmHg})$ & - & $r=0.005, p<0.001$ \\
DBP $(\mathrm{mmHg})$ & - & $r=0.045, p<0.001$ \\
Cholesterol $(\mathrm{mg} / \mathrm{dL})$ & - & $r=0.0004, p<0.001$ \\
Triglicerides $(\mathrm{mg} / \mathrm{dL})$ & - & $r=0.01, p<0.001$ \\
Creatinine $(\mathrm{mg} / \mathrm{dL})$ & - & $r=0.001, p<0.001$ \\
Glucose $(\mathrm{mg} / \mathrm{dL})$ & - & $r=0.015, p<0.001$ \\
Potassium $(\mathrm{mmol} / \mathrm{L})$ & - & $r=0.005, p<0.001$ \\
Heart rate $(\mathrm{beats} / \mathrm{min})$ & - & $r=0.015, p<0.001$ \\
hs-CRP $(\mathrm{mg} / \mathrm{dL})$ & - & $r=0.126, p<0.001$ \\
PTX3 $(\mathrm{ng} / \mathrm{mL})$ & - & $r=0.012, p=0.047$ \\
FMD $(\%)$ & - & $r=0.00001, p<0.001$ \\
CC IMT right $(\mathrm{mm})$ & - & $r=0.0002, p<0.001$ \\
CC IMT left $(\mathrm{mm})$ & - & $r=0.002, p<0.001$ \\
BMI $\left(\mathrm{kg} / \mathrm{m}^{2}\right)$ & - & $r=0.0002, p<0.001$ \\
WBC $\mu \mathrm{L}$ & - & $r=0.006, p<0.001$ \\
NEUTRO $\mu \mathrm{L}$ & - &
\end{tabular}

-, no correlation.

Table 6. Correlation of TSP-1 plasma levels with all data in Group B.

\begin{tabular}{ccc}
\hline Parameters & Thrombospondin-1 & Correlation \\
\hline Age (years) & - & $r=0.109, p<0.001$ \\
HTN duration $(\mathrm{months})$ & - & $r=0.019, p<0.001$ \\
SBP $(\mathrm{mmHg})$ & - & $r=0.00005, p=0.018$ \\
DBP $(\mathrm{mmHg})$ & - & $r=0.1069, p=0.561$ \\
Cholesterol $(\mathrm{mg} / \mathrm{dL})$ & - & $r=0.028, p=0.007$ \\
Triglicerides $(\mathrm{mg} / \mathrm{dL})$ & Positive & $r=0.329, p<0.001$ \\
Creatinine $(\mathrm{mg} / \mathrm{dL})$ & - & $r=0.09, p=0.271$ \\
Glucose $(\mathrm{mg} / \mathrm{dL})$ & - & $r=0.108, p<0.001$ \\
Potassium $(\mathrm{mmol} / \mathrm{L})$ & - & $r=0.002, p=0.167$ \\
Heart rate $(\mathrm{beats} / \mathrm{min})$ & - & $r=0.06, p<0.001$ \\
hs-CRP $(\mathrm{mg} / \mathrm{dL})$ & - & $r=0.101, p<0.001$ \\
PTX3 $(\mathrm{ng} / \mathrm{mL})$ & - & $r=0.064, p=0.863$ \\
FMD $(\%)$ & - & $r=0.036, p<0.001$ \\
CC IMT right $(\mathrm{mm})$ & - & $r=0.011, p<0.001$ \\
CC IMT left $(\mathrm{mm})$ & - & $r=0.086, p=0.648$ \\
BMI $\left(\mathrm{kg} / \mathrm{m}^{2}\right)$ & - & $r=0.334, p=0.587$ \\
WBC $\mu \mathrm{L}$ & Positive & $r=0.30, p=0.0190$ \\
NEUTRO $\mu \mathrm{L}$ & Positive &
\end{tabular}

Table 7. Correlation of TSP-1 plasma levels with all data in Group A.

\begin{tabular}{ccc}
\hline Parameters & Thrombospondin-1 & Correlation \\
\hline Triglicerides $(\mathrm{mg} / \mathrm{dL})$ & - & $r=0.0002, p<0.001$ \\
WBC $\mu \mathrm{L}$ & - & $r=0.0003, p<0.001$ \\
NEUTRO $\mu \mathrm{L}$ & - & $r=0.0002, p<0.001$ \\
\hline
\end{tabular}

Figure 1 shows that patients treated with the lowest concentration of Perindopril ( $5 \mathrm{mg} / \mathrm{day}$ ) had the lowest TSP-1 plasma levels, compared with those who were under treatment with the highest concentration of Perindopril available on the market (10 mg/day). 

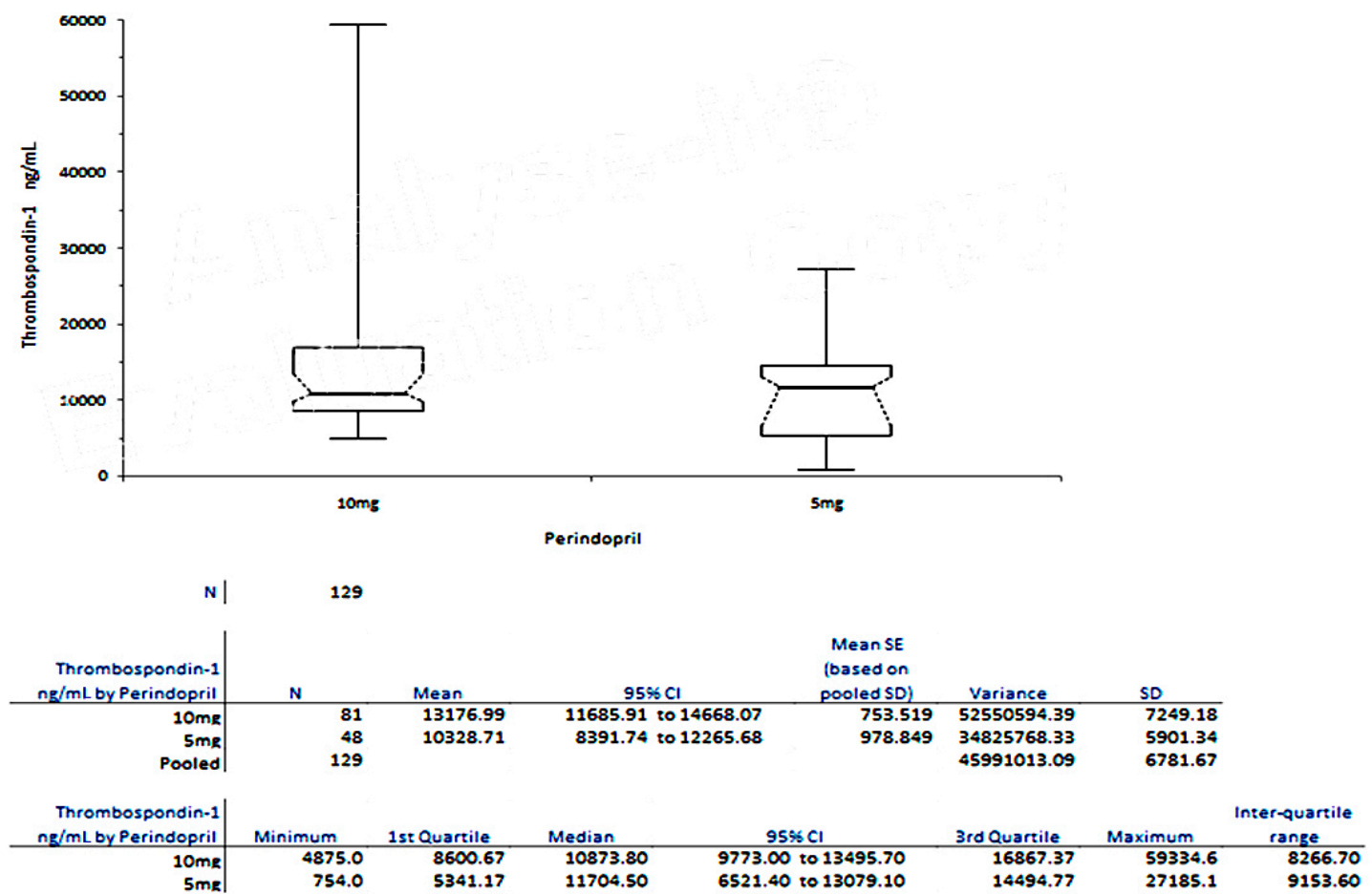

Figure 1. Variation of TSP-1 plasma levels in Group C, under different concentrations of Perindopril.

From Figure 2 it can be noticed that women have higher plasma levels compared with men.
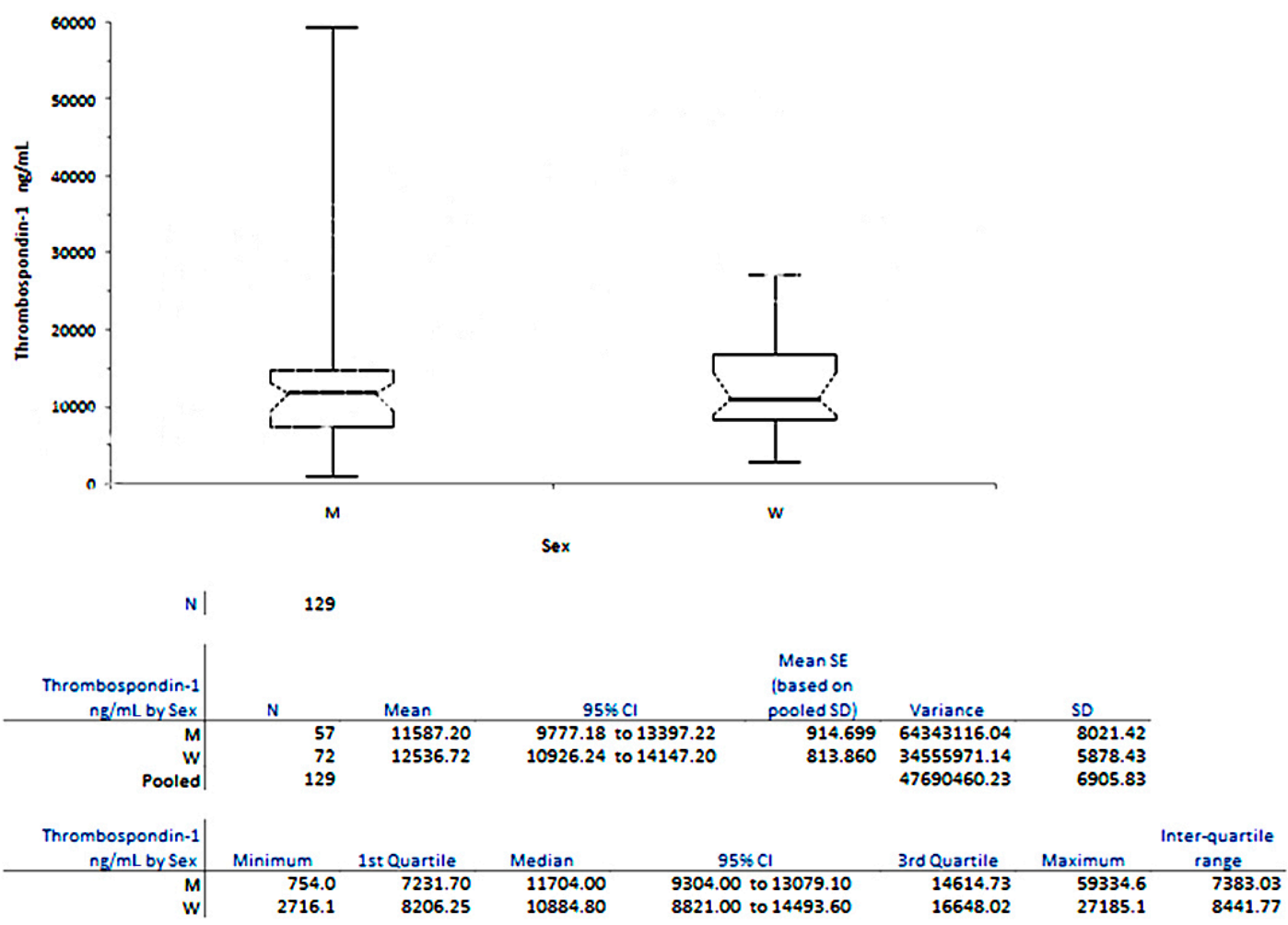

Figure 2. Variation of TSP-1 plasma levels in men and women in Group C. 
From Figure 3 it can be noticed that patients under treatment with different classes of antihypertensive drugs (beta blockers, calcium channel blockers, and diuretics) had TSP-1 plasma levels lower than those under treatment with Perindopril (Group C).

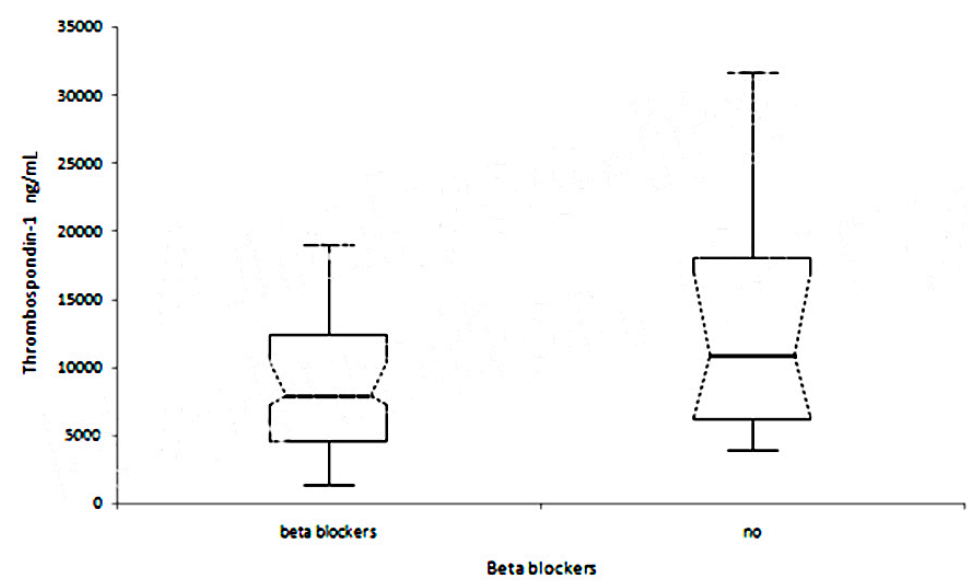

N| $\quad 117$

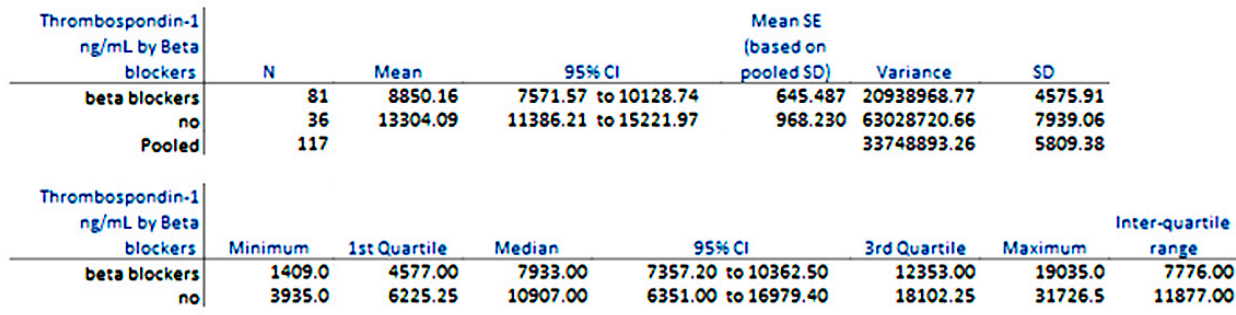

(a)

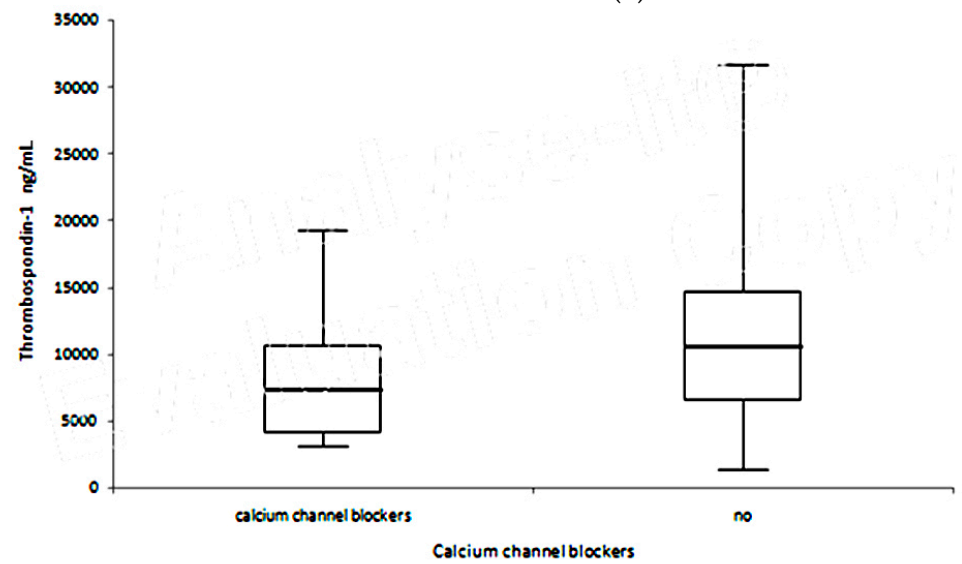

$\mathrm{N} \mid \quad 117$

\begin{tabular}{|c|c|c|c|c|c|c|}
\hline $\begin{array}{c}\text { Thrombospondin-1 } \\
\mathrm{ng} / \mathrm{mL} \text { by Calcium } \\
\text { channel blockers }\end{array}$ & $\mathrm{N}$ & Mean & $95 \% \mathrm{Cl}$ & $\begin{array}{c}\text { Mean SE } \\
\text { (based on } \\
\text { pooled SD) }\end{array}$ & Variance & SD \\
\hline $\begin{array}{r}\text { calcium channel } \\
\text { blockers }\end{array}$ & 39 & 7887.59 & 6003.64 to 9771.55 & 951.104 & 17470617.35 & 4179.79 \\
\hline $\begin{array}{r}\text { no } \\
\text { Pooled }\end{array}$ & $\begin{array}{r}78 \\
117\end{array}$ & 11387.10 & 10054.94 to 12719.26 & 672.532 & $\begin{array}{l}44068065.70 \\
35279343.64\end{array}$ & $\begin{array}{l}6638.38 \\
5939.64\end{array}$ \\
\hline
\end{tabular}

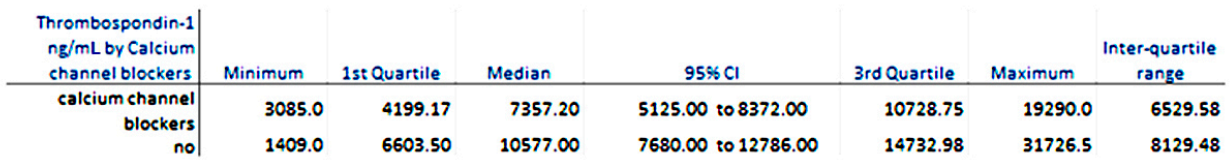

(b)

Figure 3. Cont. 


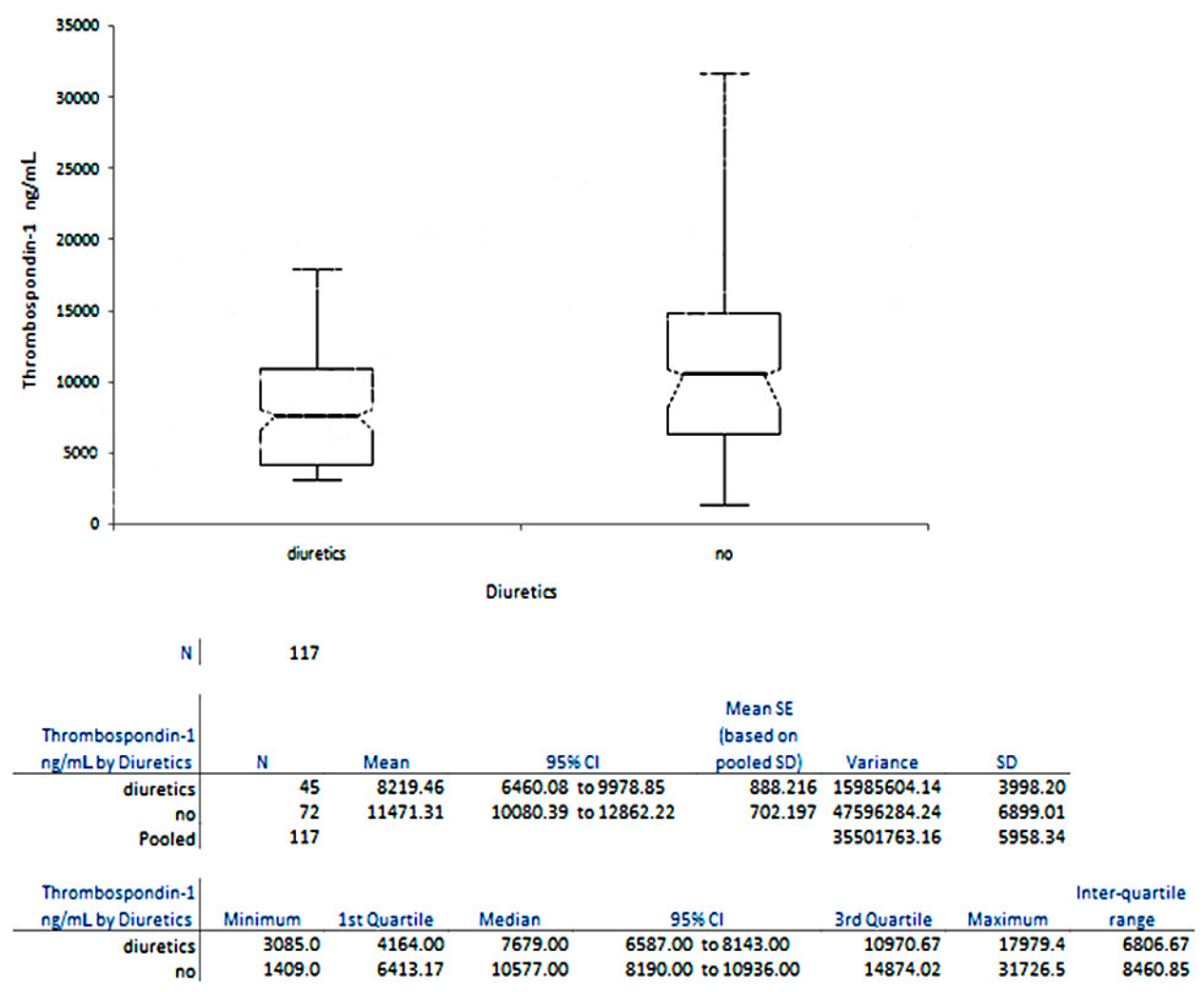

(c)

Figure 3. Variation of TSP-1 plasma levels in Group B, under different antihypertensive treatment: (a) beta blockers, (b) calcium channel blockers, and (c) diuretics.

\section{Discussion}

Perindopril belongs to the third generation of ACE inhibitors, intensively prescribed and studied. ACE inhibitors are a group of drugs used and listed as first-line agents in the treatment of hypertension, congestive heart failure, myocardial infarction, and left ventricular systolic dysfunction, and are either used alone or in combination with other types of drugs with different action mechanisms [30-36]. All of the positive effects on the pathologies mentioned previously are the consequences of their mechanism of action: firstly, they block the angiotensin (Ang)-converting enzyme the enzyme that transforms Ang I (found in the vascular endothelium of lungs and other organs and in lower concentrations in the vascular plasma) in Ang II, decreasing the circulating levels of Ang II. Due to the decreased synthesis of Ang II, the plasmatic levels of Ang I are increased, and through a feed-back phenomenon, Ang II induces the stimulation of the rennin synthesis and lowers the levels of angiotensinogen, due to its high consumption. The decreased levels of Ang II induce decreased effects of the peptide on the vascular tonus, the synthesis and liberation of aldosteron, the sodium-potassium balance, etc.

Secondly, due to the fact that ACE is identical with the enzyme that degrades bradykinin (BK), kinase II, Perindopril and other ACE inhibitors increase the bradykinin concentration and stimulate the action of endogenous kinins to produce nitric oxide (NO), prostaciclins, and EDHF (endothelium-derived hyperpolarizing factor), through the stimulation of bradykinin $\mathrm{B}_{2}$ receptors, having, as a consequence, the vascular protective effects and the reversed ED installed [34,36,37]. The inhibition of the BK degradation is the main mechanism (known at the moment) by which ACE inhibitors induce cardiovascular protection. This effect may differ between ACE inhibitors as it depends on the degree of the tissue affinity and on their binding to BK. Additionally, ACE inhibitors have a higher affinity for bradykinin sites compared with the affinity for Ang I, so they primarily inhibit BK degradation and then the production of Ang II [38]. 
We choose Perindopril for this study because of its pharmacokinetics and pharmacodynamic properties: the highest bioavailability $(75 \%)$, the highest terminal elimination half-life of the major active ingredient (30-120 h), a higher time to reach maximum plasma concentration, the highest affinity for BK binding sites when compared with other substances from its class: Enalapril, Lisinopril, Quinapril, Ramipril [39], high lipophilicity and tissue penetration among other ACE inhibitors [38], prolonged duration of action [39], prolonged inhibition of ACE ( $>48 \mathrm{~h}$ ) [40], and $24 \mathrm{~h}$ efficacy, which implies a low number of administrations per day and a higher compliance for patients to the treatment [39]. Moreover, it has been shown to exert potent anti-apoptotic actions on the endothelium and on the cardiac myocytes [38]. Regarding the study that we performed, the results presented in Tables 2 and 3 clearly suggest the fact that, although the patients under chronic treatment with Perindopril have more risk factors compared with those under treatment with other antihypertensive drugs (beta blockers, calcium channel blockers, diuretics) - this conclusion being based on higher cholesterol levels, BMI, number of smokers, level of systemic inflammation (ESR and hs-CRP plasma levels) - the degree of ED is lower in this group (reflected by the FMD level) and the degree of local endothelial inflammation is also lower in the same group (reflected through the PTX3 plasma levels, an acute inflammatory marker, secreted by the endothelial cells). We can conclude that, based on these parameters, the endothelial function is better preserved by an ACE inhibitor than any other antihypertensive drugs (beta blockers, calcium channel blockers, diuretics) in a chronic treatment.

As for the TSP-1 plasma levels, although the difference between the groups have not reached the level of statistical significance $(p=0.08, p<0.05)$, the plasma values of this biomarker are higher in the group of patients treated with Perindopril (Group C). Based on the evidence reported in the literature and discussed in the introduction about the effects of TSP-1 on the vascular endothelium (although they are contradictory and opposing), in our study, and based on the studies reported by others, the low levels of TSP-1 might be an inducer of VSMC proliferation and that higher levels of TSP-1 could induce an anti-proliferative effect on VSMCs by reducing its density (throughout the binding of TSP-1 C-terminal domain to CD47-binding peptide) [40-43]. Thus, in normal low levels, TSP-1 could act as an inducer of VSMC proliferation and, in pathological conditions (e.g., atherosclerosis), whereas TSP-1 is upregulated, high levels of TSP-1 could act as an anti-proliferative agent, although the effects of TSP-1 could be different in function of the pathology concerned [6].

TSP-1 has been also reported to play an important role in decreasing inflammation and, thus, having an anti-inflammatory action, due to its interaction with CD47 receptor expressed on T-cells and polymorphonuclear cells [44]. So, based on our study, we may say that, in Group C, the patients under chronic treatment with Perindopril, have a more decreased level of endothelial inflammation, reflected through the TSP-1 plasma levels and not only through PTX3.

No correlation had been found between TSP-1 serum levels and the disease severity and/or duration, as Tables 5 and 6 show.

The data found in the literature about the relationship between TSP-1 and leucocytes [45-48] confirms the same idea found in our study, that TSP-1 plays an important role in the recruitment of monocytes and macrophages to the site of tissue inflammation or injury. In the present study, we found positive correlation between TSP- 1 and triglycerides, leucocytes, and neutrophils, correlations that show the local, vascular, inflammatory site in patients under chronic treatment with other antihypertensive drugs, except Perindopril. This is one more argument that Perindopril controls better the local endothelial inflammation and the vascular function.

In a study performed by Xia et al. in 2011 [49], authors suggested that TSP-1 expression might be involved in the regulation of fibroblast phenotypes and that it could prevent the left ventricular hypertrophy in pressure-overloaded hearts, so we may add another positive effect proved by this study for Perindopril: its anti-fibrotic effect.

We also found that the TSP-1 plasma levels are lower for men than for women.

This study has several limitations, including the relatively low number of patients examined and the short observation time. Additionally, the study results cannot explain the molecular mechanisms by 
which Perindopril increases plasma TSP-1 levels in hypertensive patients with endothelial dysfunction; therefore, additional studies are needed to fully assess the effects of TSP-1 on vasculature.

\section{Materials and Methods}

This prospective, comparative study was performed in the Cardiology Clinic of the City Hospital of Timisoara (a city in the western part of Romania), from February 2015 to July 2016. It involved a number of 351 patients, 105 normotensive patients (Group A), and 246 hypertensive patients (Group B and C), matched by age and sex.

\subsection{Patient Selection}

The normotensive patients (Group A), the control group, were initially examined for suspicion of HTN, but the diagnosis had not been confirmed by the $24 \mathrm{~h}$ ambulatory monitoring device.

The hypertensive patients were divided into two subgroups: Group B $(n=117)$ included patients under chronic treatment with a $\beta$ blocker (nebivolol $5 \mathrm{mg} /$ day; metoprolol 50 or $100 \mathrm{mg} /$ day; or bisoprolol, 5 or 10mg/day), a calcium channel blocker (amlodipine, 5 or 10mg/day; or lercanidipine, 10 or $20 \mathrm{mg} /$ day), or a diuretic (indapamide, 1.5 or $2.5 \mathrm{mg} /$ day; or furosemide, $20 \mathrm{mg} /$ day + spironolactone, $50 \mathrm{mg} /$ day).

Patients in Group C $(n=129)$ were under chronic treatment with Perindopril (5 or $10 \mathrm{mg} /$ day), an angiotensin-converting enzyme (ACE) inhibitor.

Hypertensive patients were included under the following criteria: age $>18$ years old, who were diagnosed with essential arterial hypertension (blood pressure levels $>140 / 90 \mathrm{mmHg}$ ) for at least one year and had received monotherapy with one of the drugs mentioned above.

Patients with other pathologies including atherosclerotic disease, diabetes, coronary artery disease, heart failure, kidney disease, asthma, hepatic disease, and acute or chronic inflammatory conditions were excluded. Additionally, patients treated with other ACE inhibitors or ARBs (antagonist receptor blockers) were excluded from this study due to the similar action in reversing the endothelial dysfunction.

All of the participants from the present study agreed to participate voluntarily and provided written informed consent.

Hypertensive patients (Group B and C) underwent screening including a physical examination and a medical history (duration of hypertension, current treatment, familial history, and other associated medical pathologies).

\subsection{Laboratory Analysis}

Patients were fasted for $>10 \mathrm{~h}$ and venous blood samples were withdrawn early in the morning, in a temperature-controlled room. Standard biochemical analysis (e.g., serum glucose, creatinine, triglycerides, total cholesterol) was performed in the hospital laboratory by routine methods. Plasma concentrations of hs-CRP (high-sensitivity C-reactive protein), PTX3 (pentraxin-3), and TSP-1 were determined at Bioclinica SA Laboratory in Timisoara. PTX3 and TSP-1 plasma levels were determined by quantitative sandwich enzyme immunoassays ( $\mathrm{R}$ and D Systems, Minneapolis, MN, USA) and plasma hs-CRP levels were measured using CRP Ultra Kits (Abbott Diagnostics, Wiesbaden, Hesse, Germany), using a highly sensitive immunoturbidimetric method. All of these methods are standardized methods, so we consider that there is no need to repeat the methods here.

\subsection{Arterial Pressure}

Blood pressure was measured three times in the right brachial artery of each patient, in the same temperature-controlled room, after $30 \mathrm{~min}$ of rest, with the patient in a supine position. The reported value of pressure was expressed as the mean of three measurements. We calculated the mean arterial blood pressure as follows: $(2 \times$ diastolic pressure + systolic pressure $) / 3$. 


\subsection{Assessment of Flow-Mediated Dilation (FMD)}

The assessment of flow-mediated dilation is, nowadays, the most common, non-invasive technique and is used to evaluate the vascular endothelial function in humans. It was developed in 1992 and, since its inception, ongoing efforts have been made to perform the original methodology in a more accurate, exact, and precise method. It consists of the capacity of the blood vessel to adapt to the increasing of blood pressure, a process that is dependent of the endothelium production of NO [50-53].

This procedure was performed after the patient fasted, stopped taking the vasoactive medication, and did not smoke for at least $10 \mathrm{~h}$, based on the literature data. After resting for $10 \mathrm{~min}$ in a quiet room, the patient was placed in a supine position. His arm was placed in a comfortable position and the brachial artery was imaged above the antecubital fosa in the longitudinal plane, using a linear transducer in $9 \mathrm{MHz}$ mode. The diameter of the brachial artery was measured manually with electronic calipers. In order to produce the local ischemia (to evaluate the ability of the endothelium to produce $\mathrm{NO}$ ), the cuff of a manometer was inflated to a pressure of $50 \mathrm{mmHg}$ higher than the systolic blood pressure of the patient. After $5 \mathrm{~min}$ of hyperemia, the cuff was released, increasing the diameter of the brachial artery. The maximum diameter was measured $1 \mathrm{~min}$ after the cuff release and the FMD was defined as the percent change in diameter from the rest to $1 \mathrm{~min}$ after the ischemia, considering a $20 \%$ increase as normal (healthy endothelium) and under $20 \%$ as endothelial dysfunction.

\subsection{Carotid Intima-Media Thickness (IMT)}

Carotid intima-media thickness was determined, as agreed in the Mannheim Consensus [54], at the common carotid artery at baseline in both carotid arteries, with the same equipment, a General Electric medical system VIVID S5 (General Electric Co., Horten, Norway) equipped with a $9 \mathrm{MHz}$ linear array transducer (General Electric Co., Horten, Norway). Patients were examined in a supine position and the IMT was given by the built-in software (5432774-167, General Electric Co., Horten, Norway) of the ultrasound system. The reported value was the mean values of three measurements in each patient for the left and for the right carotid, $1 \mathrm{~cm}$ before the bifurcation. The following were considered as normal values: $0.9-1.1 \mathrm{~mm}$, and values $>1.2 \mathrm{~mm}$ as the presence of atherosclerotic plaque.

\subsection{Echocardiography}

The echocardiography was performed using a high-resolution ultrasonography medical system, VIVID S5, to assess the effects of hypertension on the structures and functions of the heart. We excluded patients with low ejection fractions $(<40 \%)$, to avoid the interference in our results regarding the ED. The parameters evaluated included the diameter of the left atrium (DLA), the dimensions of the interventricular septum (IVS), posterior wall of the left ventricle (PWLV), the end diastolic diameter of the left ventricle (EDLV), the ejection fraction (EF), and the shortening fraction (SF).

All of the measurements were performed by the same certified physician.

\subsection{Statistical Analysis}

The numerical data was presented as mean \pm standard deviation (SD) and the categorical data was presented as the frequency (\%). Differences among groups were analyzed using ANOVA and Kruskal-Wallis tests. Correlations between groups or variables were found using Spearman's correlation coefficient. All statistical analyses were performed using SPSS v.17 statistical software (v.17, SPSS Inc., Chicago, IL, USA). A $p$-value $<0.05$ was considered statistically significant.

\subsection{Compliance with the Ethical Standards}

The present study has been approved by the Ethical Committee (29 June 2016) of the "Victor Babes" University of Medicine and Pharmacy, Timisoara, Romania, no. 7/2016. All procedures performed in this study with human participants were in accordance with the ethical standards of the institutional 
research committee and with the 1964 Helsinki declaration and its later amendments or comparable ethical standards.

\section{Conclusions}

The present study is innovative because, to our knowledge, no other study assessed the efficacy of Perindopril in hypertensive patients with endothelial dysfunction by quantifying TSP-1 plasma levels, compared with other antihypertensive drugs such as beta blockers, calcium channel blockers, and diuretics. Compared with other antihypertensive drugs that were studied here, Perindopril has better properties in reversing and controlling the processes of endothelial dysfunction. In the future, a study that quantifies the effects of an ARB (angiotensin receptor blocker) on TSP-1 plasma levels in hypertensive patients with ED will be necessary.

Acknowledgments: This work was supported by the grant PII-C4-TC-2016/16441-09 offered by the "Victor Babes" University of Medicine and Pharmacy of Timisoara, Romania.

Author Contributions: All authors approved the final manuscript and had input in revising it for intellectual content and style. Valentina Buda, Minodora Andor, Lucian Petrescu, Carmen Cristescu, and Mirela Cleopatra Tomescu conceived and designed the study, Minodora Andor, Ioana Citu, and Dana Emilia Baibata investigated the patients, Melania Munteanu and Octavian Cretu contributed with reagents and analysis tools, Minodora Andor, Calin Muntean, Valentina Buda, and Mirela Voicu analyzed the data, and Valentina Buda, Lucian Petrescu, and Carmen Cristescu wrote the paper.

Conflicts of Interest: The authors declare no conflict of interest.

\section{Abbreviations}

$\begin{array}{ll}\text { ACE inhibitors } & \text { angiotensin-converting enzyme inhibitors } \\ \text { Ang II } & \text { angiotensin II } \\ \text { BMI } & \text { body mass index } \\ \text { CC-IMT } & \text { common carotid intima-media thickness } \\ \text { DBP } & \text { diastolic blood pressure } \\ \text { DLA } & \text { diameter of the left atrium } \\ \text { ECM } & \text { extracellular matrix } \\ \text { ED } & \text { endothelial dysfunction } \\ \text { EDLV } & \text { end diastolic diameter of left ventricle } \\ \text { EDHF } & \text { endothelial derived hyperpolarizing factor } \\ \text { EF } & \text { ejection fraction } \\ \text { FMD } & \text { flow-mediated vasodilatation } \\ \text { HTN } & \text { hypertension } \\ \text { hs-CRP } & \text { high-sensitivity C-reactive protein } \\ \text { IVS } & \text { interventricular septum } \\ \text { MONO } & \text { monocytes } \\ \text { NEUTRO } & \text { neutrocytes, neutrophils } \\ \text { NO } & \text { nitric oxide } \\ \text { PAI } & \text { platelet activator inhibitor } \\ \text { PTX3 } & \text { pentraxin-3 } \\ \text { PWLV } & \text { posterior wall of the left ventricle } \\ \text { SD } & \text { standard deviation } \\ \text { SBP } & \text { systolic blood pressure } \\ \text { SGC } & \text { soluble guanylatecyclase } \\ \text { TGF } & \text { transforming growth factor } \\ \text { TSP-1 } & \text { thrombospondin-1 } \\ \text { VSMCs } & \text { vascular smooth muscle cells } \\ \text { WBC } & \text { white blood cells } \\ & \end{array}$




\section{References}

1. Isenberg, J.S.; Martin-Manso, G.; Maxhimer, J.B.; Roberts, D.D. Regulation of nitric oxide signalling by thrombospondin 1: Implications for anti-angiogenic therapies. Nat. Rev. Cancer 2009, 9, 182-194. [CrossRef] [PubMed]

2. Esemuede, N.; Lee, T.; Pierre-Paul, D.; Sumpio, B.E.; Gahtan, V. The role of thrombospondin-1 in human disease. J. Surg. Res. 2004, 122, 135-142. [CrossRef] [PubMed]

3. Bagavandoss, P.; Wilks, J.W. Specific inhibition of endothelial cell proliferation by thrombospondin. Biochem. Biophys. Res. Commun. 1990, 170, 867-872. [CrossRef]

4. Iruela-Arispe, M.L.; Bornstein, P.; Sage, H. Thrombospondin exerts an antiangiogenic effect on cord formation by endothelial cells in vitro. Proc. Natl. Acad. Sci. USA 1991, 88, 5026-5030. [CrossRef] [PubMed]

5. Mustonen, E.; Ruskoaho, H.; Rysä, J. Thrombospondin-4, tumour necrosis factor-like weak inducer of apoptosis (TWEAK) and its receptor Fn14: Novel extracellular matrix modulating factors in cardiac remodelling. Ann. Med. 2012, 44, 793-804. [CrossRef] [PubMed]

6. Krishna, S.M.; Golledge, J. The role of thrombospondin-1 in cardiovascular health and pathology. Int. J. Cardiol. 2013, 168, 692-706. [CrossRef] [PubMed]

7. Kaiser, R.; Frantz, C.; Bals, R.; Wilkens, H. The role of circulating thrombospondin-1 in patients with precapillary pulmonary hypertension. Respir. Res. 2010. [CrossRef] [PubMed]

8. Jaffé, E.R. Methemoglobinemia in the differential diagnosis of cyanosis. Hosp. Pract. 1985, 20, 92-96. [CrossRef]

9. Kobayashi, S.; Yamamoto, T. The molecular biologic study of the expression of thrombospondin in vascular smooth muscle cells and mesangial cells. J. Diabet. Complicat. 1991, 5, 121-123. [CrossRef]

10. Mosher, D.F.; Doyle, M.J.; Jaffe, E.A. Synthesis and secretion of thrombospondin by cultured human endothelial cells. J. Cell Biol. 1982, 93, 343-348. [CrossRef] [PubMed]

11. Chen, H.; Herndon, M.E.; Lawler, J. The cell biology of thrombospondin-1. Matrix. Biol. 2000, 19, 597-614. [CrossRef]

12. Jiménez, B.; Volpert, O.V.; Crawford, S.E.; Febbraio, M.; Silverstein, R.L.; Bouck, N. Signals leading to apoptosis-dependent inhibition of neovascularization by thrombospondin-1. Nat. Med. 2000, 6, 41-48. [CrossRef] [PubMed]

13. Liu, A.; Mosher, D.F.; Murphy-Ullrich, J.E.; Goldblum, S.E. The counteradhesive proteins, thrombospondin 1 and SPARC/osteonectin, open the tyrosine phosphorylation-responsive paracellular pathway in pulmonary vascular endothelia. Microvasc. Res. 2009, 77, 13-20. [CrossRef] [PubMed]

14. Liu, A.; Garg, P.; Yang, S.; Gong, P.; Pallero, M.A.; Annis, D.S.; Liu, Y.; Passaniti, A.; Mann, D.; Mosher, D.F.; et al. Epidermal growth factor-like repeats of thrombospondins activate phospholipase Cgamma and increase epithelial cell migration through indirect epidermal growth factor receptor activation. J. Biol. Chem. 2009, 284, 6389-6402. [CrossRef] [PubMed]

15. Stenina, O.I.; Byzova, T.V.; Adams, J.C.; McCarthy, J.J.; Topol, E.J.; Plow, E.F. Coronary artery disease and the thrombospondin single nucleotide polymorphisms. Int. J. Biochem. Cell Biol. 2004, 36, 1013-1030. [CrossRef] [PubMed]

16. Frangogiannis, N.G.; Ren, G.; Dewald, O.; Zymek, P.; Haudek, S.; Koerting, A.; Winkelmann, K.; Michael, L.H.; Lawler, J.; Entman, M.L. Critical role of endogenous thrombospondin-1 in preventing expansion of healing myocardial infarcts. Circulation 2005, 111, 2935-2942. [CrossRef] [PubMed]

17. Chatila, K.; Ren, G.; Xia, Y.; Huebener, P.; Bujak, M.; Frangogiannis, N.G. The role of the thrombospondins in healing myocardial infarcts. Cardiovasc. Hematol. Agents Med. Chem. 2007, 5, 21-27. [CrossRef] [PubMed]

18. Miyata, Y.; Sakai, H. Thrombospondin-1 in urological cancer: Pathological role, clinical significance, and therapeutic prospects. Int. J. Mol. Sci. 2013, 14, 12249-12272. [CrossRef] [PubMed]

19. Rusnati, M.; Urbinati, C.; Bonifacio, C.; Presta, M.; Taraboletti, G. Thrombospondin-1 as a paradigm for the development of antiangiogenic agents endowed with multiple mechanisms of action. Pharmaceuticals 2010, 3, 1241-1278. [CrossRef] [PubMed]

20. Bonnefoy, A.; Moura, R.; Hoylaerts, M.F. The evolving role of thrombospondin-1 in hemostasis and vascular biology. Cell Mol. Life Sci. 2008, 65, 713-727. [CrossRef] [PubMed]

21. Bonnefoy, A.; Hoylaerts, M.F. Thrombospondin-1 in von Willebrand factor function. Curr. Drug Targets 2008, 9, 822-832. [CrossRef] [PubMed] 
22. Carlson, C.B.; Lawler, J.; Mosher, D.F. Structures of thrombospondins. Cell Mol. Life Sci. 2008, 65, 672-686. [CrossRef] [PubMed]

23. Feitsma, K.; Hausser, H.; Robenek, H.; Kresse, H.; Vischer, P. Interaction of thrombospondin-1 and heparansulfate from endothelial cells. Structural requirements of heparansulfate. J. Biol. Chem. 2000, 275, 9396-9402. [CrossRef] [PubMed]

24. Dawson, D.W.; Pearce, S.F.; Zhong, R.; Silverstein, R.L.; Frazier, W.A.; Bouck, N.P. CD36 mediates the In vitro inhibitory effects of thrombospondin-1 on endothelial cells. J. Cell. Biol. 1997, 138, 707-717. [CrossRef] [PubMed]

25. Gao, A.G.; Lindberg, F.P.; Dimitry, J.M.; Brown, E.J.; Frazier, W.A. Thrombospondin modulates $\alpha \mathrm{V} \beta 3$ function through integrin-associated protein. J. Cell Biol. 1996, 135, 533-544. [CrossRef] [PubMed]

26. Baenziger, N.L.; Brodie, G.N.; Majerus, P.W. A thrombin-sensitive protein of human platelet membranes. Proc. Natl. Acad. Sci. USA 1971, 68, 240-243. [CrossRef] [PubMed]

27. Gutierrez, L.S. The role of thrombospondin 1 on intestinal inflammation and carcinogenesis. Biomark. Insights 2008, 3, 171-178. [PubMed]

28. Grimbert, P.; Bouguermouh, S.; Baba, N.; Nakajima, T.; Allakhverdi, Z.; Braun, D.; Saito, H.; Rubio, M.; Delespesse, G.; Sarfati, M. Thrombospondin/CD47 interaction: A pathway to generate regulatory T cells from human CD4+ CD25- T cells in response to inflammation. J. Immunol. 2006, 177, 3534-3541. [CrossRef] [PubMed]

29. Avice, M.N.; Rubio, M.; Sergerie, M.; Delespesse, G.; Sarfati, M. CD47 ligation selectively inhibits the development of human naive $\mathrm{T}$ cells into Th1 effectors. J. Immunol. 2000, 165, 4624-4631. [CrossRef] [PubMed]

30. Buda, V.; Andor, M.; Cristescu, C.; Voicu, M.; Suciu, L.; Suciu, M.; Tomescu, M. Blockers of the RAA system: Perindopril and candesartan and their implication on endothelial dysfunction. Med. Evol. 2014, XX, 509-517.

31. Buda, V.; Andor, M.; Cristescu, C.; Voicu, M.; Suciu, L.; Muntean, C.; Cretu, O.; Baibata, D.E.; Gheorghiu, C.M.; Tomescu, M.C. The influence of perindopril on PTX3 plasma levels in hypertensive patients with endothelial dysfunction. Farmacia 2016, 64, 382-389.

32. Buda, V.; Tomescu, M.; Cristescu, C. The relationship between the bradykinins, RAAS and ACE inhibitors: An overview. Med. Evol. 2014, XX, 301-309.

33. Cockcroft, J.R. ACE inhibition in hypertension. Am. J. Cardiovasc. Drugs 2007, 7, 3003-3317. [CrossRef]

34. Hanif, K.; Bid, K.H.; Konwar, R. Reinventing the ACE inhibitors: Some old and new implications of ACE inhibition. Hypertens. Res. 2010, 33, 11. [CrossRef] [PubMed]

35. Mancia, G.; Fagard, R.; Narkiewicz, K.; Redon, J.; Zanchetti, A.; Böhm, M.; Christiaens, T.; Cifkova, R.; de Backer, G.; Dominiczak, A.; et al. 2013 ESH/ESC guidelines for the management of arterial hypertension: The Task Force for the Management of Arterial Hypertension of the European Society of Hypertension (ESH) and of the European Society of Cardiology (ESC). Eur. Heart J. 2013, 34, 2159-2219. [CrossRef] [PubMed]

36. Fox, K. Contribution of perindopril to cardiology: 20 years of success. Eur. Heart J. Suppl. 2007, 9, E10-E19. [CrossRef]

37. Ferrari, R. Angiotensin-converting enzyme inhibition in cardiovascular disease evidence with perindopril. Expert. Rev. Cardiovasc. Ther. 2005, 3, 15-29. [CrossRef] [PubMed]

38. Brugts, J.J.; Ferrari, R.; Simoons, M.L. Angiotensin-converting enzyme inhibition by perindopril in the treatment of cardiovascular disease. Expert. Rev. Cardiovasc. Ther. 2009, 7, 345-360. [CrossRef] [PubMed]

39. Louis, W.J.; Conway, E.L.; Krum, H.; Workman, B.; Drummer, O.H.; Lam, W.; Phillips, P.; Howes, L.G.; Jackson, B. Comparison of the pharmacokinetics and pharmacodynamics of perindopril, cilazapril and enalapril. Clin. Exp. Pharmacol. Physiol. Suppl. 1992, 19, 55-60. [CrossRef] [PubMed]

40. Louis, W.J.; Workman, B.S.; Conway, E.L.; Worland, P.; Rowley, K.; Drummer, O.; McNeil, J.J.; Harris, G.; Jarrott, B. Single-dose and steady-state pharmacokinetics and pharmacodynamics of perindopril in hypertensive subjects. J. Cardiovasc. Pharmacol. 1992, 20, 505-511. [CrossRef] [PubMed]

41. Isenberg, J.S.; Calzada, M.J.; Zhou, L.; Guo, N.; Lawler, J.; Wang, X.Q.; Frazier, W.A.; Roberts, D.D. Endogenous thrombospondin-1 is not necessary for proliferation but is permissive for vascular smooth muscle cell responses to platelet-derived growth factor. Matrix. Biol. 2005, 24, 110-123. [CrossRef] [PubMed]

42. Isenberg, J.S.; Ridnour, L.A.; Dimitry, J.; Frazier, W.A.; Wink, D.A.; Roberts, D.D. CD47 is necessary for inhibition of nitric oxide-stimulated vascular cell responses by thrombospondin-1. J. Biol. Chem. 2006, 281, 26069-26080. [CrossRef] [PubMed] 
43. Isenberg, J.S.; Wink, D.A.; Roberts, D.D. Thrombospondin-1 antagonizes nitric oxide-stimulated vascular smooth muscle cell responses. Cardiovasc. Res. 2006, 71, 785-793. [CrossRef] [PubMed]

44. Lamy, L.; Foussat, A.; Brown, E.J.; Bornstein, P.; Ticchioni, M.; Bernard, A. Interactions between CD47 and thrombospondin reduce inflammation. J. Immunol. 2007, 178, 5930-5939. [CrossRef] [PubMed]

45. Agah, A.; Kyriakides, T.R.; Lawler, J.; Bornstein, P. The lack of thrombospondin-1 (TSP1) dictates the course of wound healing in double-TSP1/TSP2-null mice. Am. J. Pathol. 2002, 161, 831-839. [CrossRef]

46. Mansfield, P.J.; Suchard, S.J. Thrombospondin promotes chemotaxis and haptotaxis of human peripheral blood monocytes. J. Immunol. 1994, 153, 4219-4229. [PubMed]

47. Martin-Manso, G.; Galli, S.; Ridnour, L.A.; Tsokos, M.; Wink, D.A.; Roberts, D.D. Thrombospondin 1 promotes tumor macrophage recruitment and enhances tumor cell cytotoxicity of differentiated U937 cells. Cancer Res. 2008, 68, 7090-7099. [CrossRef] [PubMed]

48. Daniel, C.; Schaub, K.; Amann, K.; Lawler, J.; Hugo, C. Thrombospondin-1 is an endogenous activator of TGF- $\beta$ in experimental diabetic nephropathy in vivo. Diabetes 2007, 56, 2982-2989. [CrossRef] [PubMed]

49. Xia, Y.; Dobaczewski, M.; Gonzalez-Quesada, C.; Chen, W.; Biernacka, A.; Li, N.; Lee, D.W.; Frangogiannis, N.G. Endogenous thrombospondin 1 protects the pressure-overloaded myocardium by modulating fibroblast phenotype and matrix metabolism. Hypertension 2011, 58, 902-911. [CrossRef] [PubMed]

50. Thijssen, D.H.; Black, M.A.; Pyke, K.E.; Padilla, J.; Atkinson, G.; Harris, R.A.; Parker, B.; Widlansky, M.E.; Tschakovsky, M.E.; Green, D.J. Assessment of flow-mediated dilation in humans: A methodological and physiological guideline. Am. J. Physiol. Heart Circ. Physiol. 2011, 300, H2-H12. [CrossRef] [PubMed]

51. Harris, R.A.; Nishiyama, S.K.; Wray, D.W.; Richardson, R.S. Ultrasound assessment of flow-mediated dilation. Hypertension 2010, 55, 1075-1085. [CrossRef] [PubMed]

52. Andor, M.; Tomescu, M. Endothelial dysfunction-methods of assessment and pharmacological approach in cardiovascular diseases. TMJ 2005, 55, 58-63.

53. Correti, M.C.; Anderson, T.J.; Benjamin, E.J.; Celemajer, D.; Charbonneau, F.; Creager, M.A.; Deanfield, J.; Drexler, H.; Gerhard-Herman, M.; Herrington, D.; et al. Guidelines for the ultrasound assessment of endothelial dependent flow-mediated vasodilatation of the brachial artery: A report of the international brachial artery reactivity task force. JACC 2002, 39, 257-265. [CrossRef]

54. Touboul, P.J.; Hennerici, M.G.; Meairs, S.; Adams, H.; Amarenco, P.; Bornstein, N.; Csiba, L.; Desvarieux, M.; Ebrahim, S.; Hernandez, R.; et al. Mannheim carotid intima-media thickness and plaque consensus (2004-2006-2011). Cerebrovasc. Dis. 2012, 34, 290-296. [CrossRef] [PubMed] 